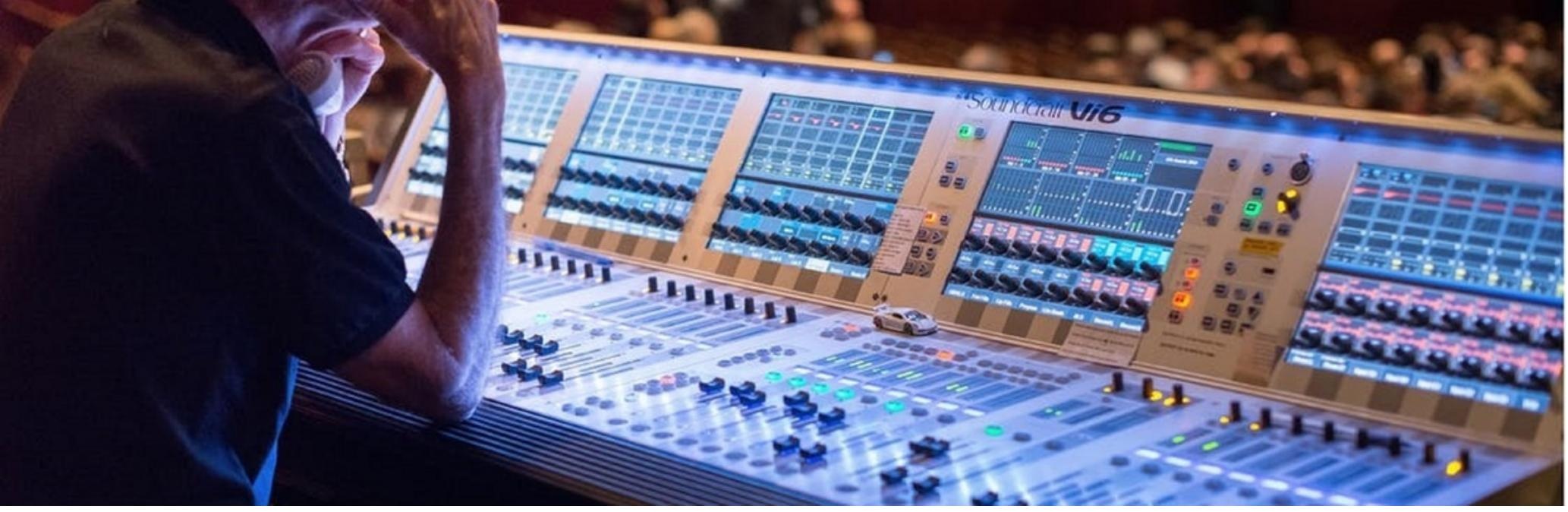

\title{
Digitaler Klang? - Digital sound?
}

$\begin{aligned} \text { Authors: } & \text { Leander Hotaki } \\ \text { Submitted: } & \text { 8. September } 2019 \\ \text { Published: } & 11 . \text { September } 2019 \\ \text { Volume: } & 6 \\ \text { Issue: } & 9 \\ \text { Affiliation: } & \text { "Albert Konzerte" Freiburg, Germany. } \\ \text { Languages: } & \text { German } \\ \text { Keywords: } & \text { music app, digital world, futur of the classic music. } \\ \text { Categories: } & \text { Performing Arts, Music } \\ \text { DOI: } & 10.17160 / \text { josha.6.9.598 }\end{aligned}$

Abstract:

Leander Hotaki is since 2010 the director of the German program called "Albert Konzerte" which is a program in charge of making possible to bring the greatest artist of the World to Freiburg and to make the most wonderful concerts in the south-west of Germany. In fact, he also promotes the work of the best students in the field of dramaturge or music in many universities in Germany and writes columns about different topics around music and musicians. This time he writes more deeply about an impressive digital music mediation on the net called "Idagio".

\section{JOSHA Jouna a csecterea Humanities and Arts}




\section{Digitaler Klang?}

\author{
By Dr. Leander Hotaki
}

Digitalisierung spielt auch im Bereich der Musik eine immer größere Rolle. Nachdem man z.B. über youtube bereits eine nicht mehr überschaubare Fülle von musikalischen Ereignissen in Bild und Ton vernehmen kann, hat sich nun noch eine neue, sehr ambitionierte Möglichkeit ergeben, an eine noch größere Zahl bedeutender und wegweisender Interpretationen über das Netz zu gelangen: idagio. Dieses Angebot, zunächst kostenlos, später für je fünf Euro im Monat, hat mehrere Vorteile gegenüber den bisherigen Zugängen: Es ist von einem wirklichen Profi der Branche entwickelt worden, erfreut sich zudem der Unterstützung vieler großer Orchester und Musiker und bietet in der Tat Zugänge zur ganzen Welt der Musik, und zwar als Streaming und als Download. Natürlich muss man das ausdrücklich formulierte Ziel von idagio, Klassik allen jederzeit zugänglich zu machen und so der Klassik einen angemessenen Platz im Netz zu verschaffen, begrüßen - selbst wenn auch hier wieder wie bei allen derartigen digitalen Verfügbarkeiten das „alte“ und auch schöne Gefühl des „Haptischen“, des in die Hand Nehmens und Fühlen Könnens verloren geht. Das wahrscheinlich Klügste an diesem idagio-Projekt dürfte aber noch etwas sein, das man in den letzten Jahren beinahe völlig vergessen hatte: Nicht nur bei Konzertmitschnitten, sondern auch bei Opernaufnahmen, hat man kaum über
Klangqualität gesprochen. Das war mal völlig anders: Denken wir nur an früher hart geführte Diskussionen über Frequenzumfang, über den Klang bestimmter Boxen oder die Aussteuerungsmöglichkeiten der Verstärker - vom Auflagegewicht des Plattenspielerarmes und dessen Folgen ganz $\mathrm{zu}$ schweigen; man ging $\mathrm{zu}$ den bestbestückten Hifi-Händlern, hörte die verschiedenen Konstellationen der MusikAnlagen, empfand diese als zu dumpf, jene als zu schrill usw usw. All das spielte keine oder keine große Rolle mehr. Die Betreiber von idagio sprechen zumindest wieder vom Klang, weisen auf Extras wie den HDSound hin, haben also wenigstens das Problem erkannt. Ob sie es jedoch überzeugend lösen können und ob man sich nicht doch von alten Klangidealen entfernen muß, die man eigentlich gar nicht aufgeben will (so wenig wie das 'Haptische') - das wird sich zeigen.

\section{Dr. Leander Hotaki}

